\title{
Accurate Balance of the Polarity Kinase MARK2/Par-1 Is Required for Proper Cortical Neuronal Migration
}

\author{
Tamar Sapir, ${ }^{1}$ Sivan Sapoznik, ${ }^{1}$ Talia Levy, ${ }^{1}$ Danit Finkelshtein, ${ }^{1}$ Anat Shmueli, ${ }^{1}$ Thomas Timm, ${ }^{2}$ \\ Eva-Maria Mandelkow, ${ }^{2}$ and Orly Reiner ${ }^{1}$ \\ ${ }^{1}$ Department of Molecular Genetics, The Weizmann Institute of Science, Rehovot 76100, Israel, and 2Max Planck Unit for Structural Molecular Biology, \\ 22607 Hamburg, Germany
}

\begin{abstract}
Radial neuronal migration is key in structuring the layered cortex. Here we studied the role of MARK2/Par-1 in this process. The dual name stands for the MAP/microtubule affinity-regulating kinase 2 (MARK2) and the known polarity kinase 1 (Par-1). Reduced MARK2 levels using in utero electroporation resulted in multipolar neurons stalled at the intermediate zone border. Reintroduction of the wild-type kinase postmitotically improved neuronal migration. Our results indicated that reduction in MARK2 affected centrosomal dynamics in migrating neurons of the cerebral cortex. Increased MARK2 has been shown to destabilize microtubules, and here we show for the first time that reduced MARK2 stabilized microtubules in primary cultured neurons. Kinase-independent activity permitted multipolar-to-bipolar transition but did not restore proper migration. Increased MARK2 levels resulted in a different phenotype, which is loss of neuronal polarity. MARK2 kinase activity reduction hindered migration in the developing brain, which was rescued by increasing kinase activity. Our results stress the necessity of maintaining dynamic microtubules for proper neuronal migration. Furthermore, the exact requirements for MARK2 and its kinase activity vary during the course of neuronal migration. Collectively, our results stress the requirements for the different roles of MARK2 during neuronal migration.
\end{abstract}

Key words: neuronal migration; mental retardation; MARK2/Par-1; polarity kinase; microtubules; in utero electroporation

\section{Introduction}

The roles of MARK2/Par-1 in neuronal degeneration processes (Chin et al., 2000; I. Nishimura et al., 2004; Schneider et al., 2004) and in cell polarity (Biernat et al., 2002; Pellettieri and Seydoux, 2002; Macara, 2004) are well established. However, no function for MARK2/Par-1 in neuronal migration has been suggested so far. Two main reasons have underlain the quest for the role of this kinase during neuronal migration. The first is its role as a key polarity kinase, and the second is its function as a regulator of microtubule dynamics. The polarity pathway participates in multiple processes during CNS development (for review, see Solecki et al., 2006). Furthermore, this pathway is also involved in regulating the specification of the future axon in hippocampal neurons in dissociated primary cell culture. The morphological changes occurring in hippocampal neurons in dissociated pri-

Received Feb. 29, 2008; revised April 8, 2008; accepted April 20, 2008.

0.R. was supported in part by the Israeli Science Foundation (Grant 270/04 and equipment grant), Foundation Jérôme Lejeune, Minerva Foundation with funding from the Federal German Ministry for Education and Research, the German-Israeli collaboration Grant Gr-1905, March of Dimes Grant 6-FY07-388, a grant from the Paul Godfrey Research Foundation in Children's Diseases, the Benoziyo Center for Neurological Diseases, the Kekst Center, the Forcheimer Center, the Weizmann-Pasteur collaborative grant, support from Maurice Janin, the Jewish Communal Fund, Albert Einstein College of Medicine of Yeshiva University, and the David and Fela Shapell Family Center for Genetic Disorders Research. O.R. is an Incumbent of the Berstein-Mason professorial chair of Neurochemistry. This work was supported in part by the Deutsche Forschungsgemeinschaft and the Max-Planck-Gesellschaft (E.-M.M.). We thank Drs. Michel Bornens, Trina Schroer, Hillary Voet, Salvador Martinez, Ari Elson, Eli Arama, Juergen Wehland, Franck Polleux, Tony Barnes, Niels Galjard, and Eran Hornstein for useful comments and/or reagents.

Correspondence should be addressed to Orly Reiner, Department of Molecular Genetics, The Weizmann Institute of Science, Rehovot 76100, Israel. E-mail: orly.reiner@weizmann.ac.il.

DOI:10.1523/JNEUROSCI.0911-08.2008

Copyright $\odot 2008$ Society for Neuroscience $\quad 0270-6474 / 08 / 285710-11 \$ 15.00 / 0$ mary cell culture may be analogous to those observed in migrating neurons (Watabe-Uchida et al., 2006). An external signal is transmitted intracellularly, and $\mathrm{Cdc} 42$ is activated. Cdc42 bound to GTP recruits the complex of PAR-3, PAR-6, and atypical PKC (aPKC) (Shi et al., 2003; T. Nishimura et al., 2004; Schwamborn and Puschel, 2004; Nishimura et al., 2005), which is followed by activation of MARK2/Par-1 (Chen et al., 2006). In addition, kinases belonging to the MARK family (SAD-A and SAD-B) regulated by LKB-1 (PAR-4) have been shown to regulate neuronal polarity in vivo (Kishi et al., 2005; Barnes et al., 2007). An interesting link between centrosomal localization and positioning of the future axon has been demonstrated in hippocampal neurons in dissociated primary cell culture (de Anda et al., 2005). Cdc42 impacts a repertoire of targets including PAR-6, aPKC, PAR-3, and PAK5 (Govek et al., 2005). In migrating cerebellar neurons in vitro, some of these targets, such as Par- 6 and aPKC, localize to the centrosome together with dynein/dynactin. Modulating Par-6 or Par-4 levels inhibited centrosomal motion and neuronal migration (Solecki et al., 2004; Asada et al., 2007). The second reasoning for studying the role of Par-1/MARK2 in cortical neuronal migration stems from its important role in regulation of cytoskeletal dynamics (Timm et al., 2006), in particular microtubule dynamics (Drewes et al., 1997, 1998). A common theme among MARK2 substrates belonging to the group of microtubule-associated proteins (MAPs) is that after MARK2 phosphorylation, they detach from tubulin polymers. Known substrates include tau, MAP2/4, and DCX (Drewes et al., 1997; Schaar et al., 2004).

Based on the above considerations, we hypothesized that Par- 
1/MARK2 may play an important role during neuronal migration. Our results prove this hypothesis. Reduction in MARK2 levels resulted in multipolar neurons stalled mainly in the intermediate zone (IZ), which was rescued by adding back precise MARK2 levels. Our findings implicated kinase activity in regulating radial migration in vivo. Furthermore, reduction in MARK2 affected centrosomal motility in vivo. Reduction in MARK2 is expected to stabilize microtubules, as demonstrated for the first time in our studies. Kinase-independent activity allowed neurons to transit from the multipolar to bipolar morphology. Elevation in MARK2 levels resulted in loss of neuronal polarity, whereas reduction in MARK2 resulted in accumulation of multipolar neurons at the IZ border. We propose that MARK2 affects neuronal migration through its dual activities in regulating cellular polarity and microtubule dynamics.

\section{Materials and Methods}

In situ hybridization. In situ hybridizations were performed as described previously (Reiner et al., 2006) using cDNA templates from RIKEN mouse encyclopedia that were amplified with T3 and T7 primers and transcribed using polymerase of choice. MARK2 RNA probe was transcribed using AK045329 cDNA template, and AK079080 was used for PAK5 (Kawai and Hayashizaki, 2003). Double in situ immunostaining was done as described previously (Zimmer et al., 2004).

In utero electroporation. ICR mice at $14 \mathrm{~d}$ after gestation were anesthetized with $10 \%$ ketamine $/ 20 \mathrm{mg} / \mathrm{ml}$ xylazine ( $1 / 10$ mixture, $0.01 \mu \mathrm{l} / \mathrm{g}$ of body weight, i.p.). The uterine horns were exposed, and plasmids (0.5-1 $\mu \mathrm{l})$ mixed with Fast Green $(2 \mu \mathrm{g} / \mu \mathrm{l}$; Sigma) were microinjected by mouth pipette through the uterus into the lateral ventricles of embryos by pulled glass capillaries (Sutter Instrument). The concentration of plasmids was $0.5 \mu \mathrm{g} / \mu \mathrm{l}$ for pCAGGS-GFP and $1.5 \mu \mathrm{g} / \mu \mathrm{l}$ for short hairpin RNA (shRNA) constructs, unless otherwise indicated. Electroporation was accomplished by discharging five $35 \mathrm{mV}, 50$-ms-long pulses with 950 ms intervals, generated by a NepaGene electroporator. The pulses were delivered using 10-mm-diameter platinum-plated tweezer electrodes (Protech International) situated at either side of the head of each embryo through the uterus. Animals were killed $4 \mathrm{~d}$ after electroporation. Embryos were perfused ( $4 \%$ paraformaldehyde), and their brains were removed. Staining was done on $60-\mathrm{mm}$-thick vibratome sections. Animal protocols were approved by the Weizmann Institute Institutional Animal Care and Use Committee.

Time-lapse microscopy of organotypic slice cultures. In utero electroporation was performed as described above. To each embryo, a triple combination of plasmids was introduced, including pSuper shRNA $(1.5 \mu \mathrm{g})$, pCAGGS-GFP $(0.5 \mu \mathrm{g})$ to label the whole cell body, and centrin-RFP $(0.5$ $\mu \mathrm{g})$ to visualize the centrioles. Three days after electroporation, brains were removed into cold L-15 supplemented with glucose $(0.6 \%)$ and saturated with oxygen. Freshly isolated whole brains were cut into 300 $\mu \mathrm{m}$ coronal slices and then transferred onto inserts (MilliCell-CM; 0.4 $\mu \mathrm{m}$; Millipore) floating on serum-free medium (Neurobasal medium supplemented with B27, N2, GlutaMax, glucose, and gentamicin). Slices were incubated for $2 \mathrm{~h}$ before imaging. During time-lapse video microscopy, temperature was maintained at $37^{\circ} \mathrm{C}$ using gradient control. Each recording session lasted $1 \mathrm{~h}$ with one frame taken every $2 \mathrm{~min}$. Analysis of movies was performed using the Delta-Vision system package.

Hippocampal neurons in dissociated primary cell culture. Hippocampal neurons in dissociated primary cell culture [embryonic day 18.5 (E18.5)] were prepared from rat or from mice, as described previously (Brann et al., 2002). Neurons were transfected using the Amaxa electroporation protocol. After electroporation, neurons were stained as described previously (Schwarz and Futerman, 1996) or imaged live (in the case of EB3-GFP transfections) and analyzed using the Delta-Vision system package or Imaris software. In the case of EB3-GFP transfections, eight cells with a total of 11,375 tracks were analyzed from control cells, and six cells with a total of 5222 tracks were analyzed from MARK2 shRNAtreated cells.

Plasmids used in the study. To target MARK2 mRNA, previously pub- lished shRNA sequences were recloned into pSuper vector (Brummelkamp et al., 2002); MARK2 shRNA A: 5'-GAGGTAGCTGTGAAGATCA (Cohen et al., 2004); MARK2 shRNA C: $5^{\prime}$ GAATGAACCTGAAAGCAAA (Chen et al., 2006). Rat MARK2 or MARK2 S208A/T212A [kinase dead (KD)] cDNA that were fused to GFP and cloned into pCAGGS (BCCM/LMBP plasmid collection) and included three silent mutations in the RNA interference target site (GAGGTcGCgGTGAAGATCt) served as MARK2 ${ }^{\mathrm{R}}$ or MARK2 ${ }^{\mathrm{R}}-\mathrm{KD}$. In addition, NeuroD promoter was used for expression of MARK $2^{\mathrm{R}}$. To create a control shRNA, a nontargeting sequence (Dharmacon) was cloned into pSuper (5'-TAAGGCTATGAAGAGATAC). Its activity on several exogenous GFP fusion targets was negligible. Inactive PAK5-YFP (Matenia et al., 2005) and EB3-GFP (Stepanova et al., 2003) plasmids were described previously.

Antibodies. The following antibodies were used: anti-pTau $12 \mathrm{E} 8$ against tau phosphorylated at S262, in KXGS motif of the fourth repeat (kindly provided by Dr. Peter Seubert, Elan Pharmaceuticals, South San Francisco, CA), anti-NeuN (Millipore Bioscience Research Reagents), rabbit anti-MARK2 (SA5985; Mandelkow laboratory) anti-Pericentrin (BD Biosciences), and anti-detyrosinated $\alpha$-tubulin (clone ID5; kindly provided by Prof. Juergen Wehland, Helmholtz Centre for Infection Research, Braunschweig, Germany).

Measurements. Neuronal migration after in utero electroporation was determined using analysis from at least three different embryos and at least eight different sections. Sections were stained with 4', $6^{\prime}$-diamidino2-phenylindole (DAPI), and the different brain areas [ventricular zone (VZ)/subventricular zone (SVZ) and IZ, and deep and superficial cortical plate (CP) layers] were identified. Comparison between different treatments of the ratio of GFP-positive cells reaching the CP was statistically analyzed using Student's $t$ test.

Circularity calculations are built into ImageJ 1.29 (Wayne Rasband, $\mathrm{NIH}$ ). This function calculates object circularity using the following formula: circularity $=4 \pi\left(\right.$ area/perimeter $\left.{ }^{2}\right)$. A circularity value of 1.0 indicates a perfect circle. As the value approaches 0.0 , it indicates an increasingly elongated polygon.

For quantification of the colocalization between the GFP signal and the immunostaining signal, we used the colocalization program in the SoftWoRx suite. This feature is used to identify possible areas of colocalization throughout the image. It allows generation of a product image of two channels after subtracting a threshold value for each. A new channel that is a product of the two intensities at each data pixel is presented in false color. In addition, the Pearson coefficient of correlation is calculated. The Pearson coefficient of correlation indicates how closely the two intensities are colocalized, where full colocalization equals one.

Real-time PCR. RNA was extracted from CAD cells expressing MARK2 shRNA using TRI reagent (Sigma). First-strand cDNA synthesis was done using a kit for RT-PCR (BioLab). Primers were designed for MARK2 (5'-CGAGCCAAATTTCGCCAGA and 5'-TCAGCATCCAGGAGCAGGTTT) and HPRT (5'-GCAGTACAGCCCCAAAATGG and 5'-GGTCCTTTTCACCAGCAAGCT). Relative levels of MARK2 gene expression were normalized to the HPRT gene. Real-time PCR with Platinum SYBR Green qPCR SuperMix-UDG w/ROX (Invitrogen) was performed using Applied Biosystems 7300 Real-Time PCR System.

\section{Results}

Par-1/MARK2 is widely expressed in the developing brain, and shRNA effectively reduced its levels

MARK2 is widely expressed in the developing cerebral cortex. In situ hybridization demonstrated that the levels of MARK2 mRNA are particularly abundant in the cortical plate, VZ, and SVZ, and lower in the IZ (Fig. 1A, $B^{\prime}$ ). PAK5, which can inhibit MARK2 activity via direct binding (Matenia et al., 2005), is expressed in an increasing gradient: low in the VZ/SVZ, intermediate in the IZ, and higher in the superficial layers of the CP (Fig. $1 C$ ). Immunostaining of a brain section using anti-MARK2 antibodies (Fig. $1 D)$ matched the observations using in situ hybridization. Higher levels of MARK2 were noted in the CP and in the VZ/SVZ, and lower levels in the IZ. 

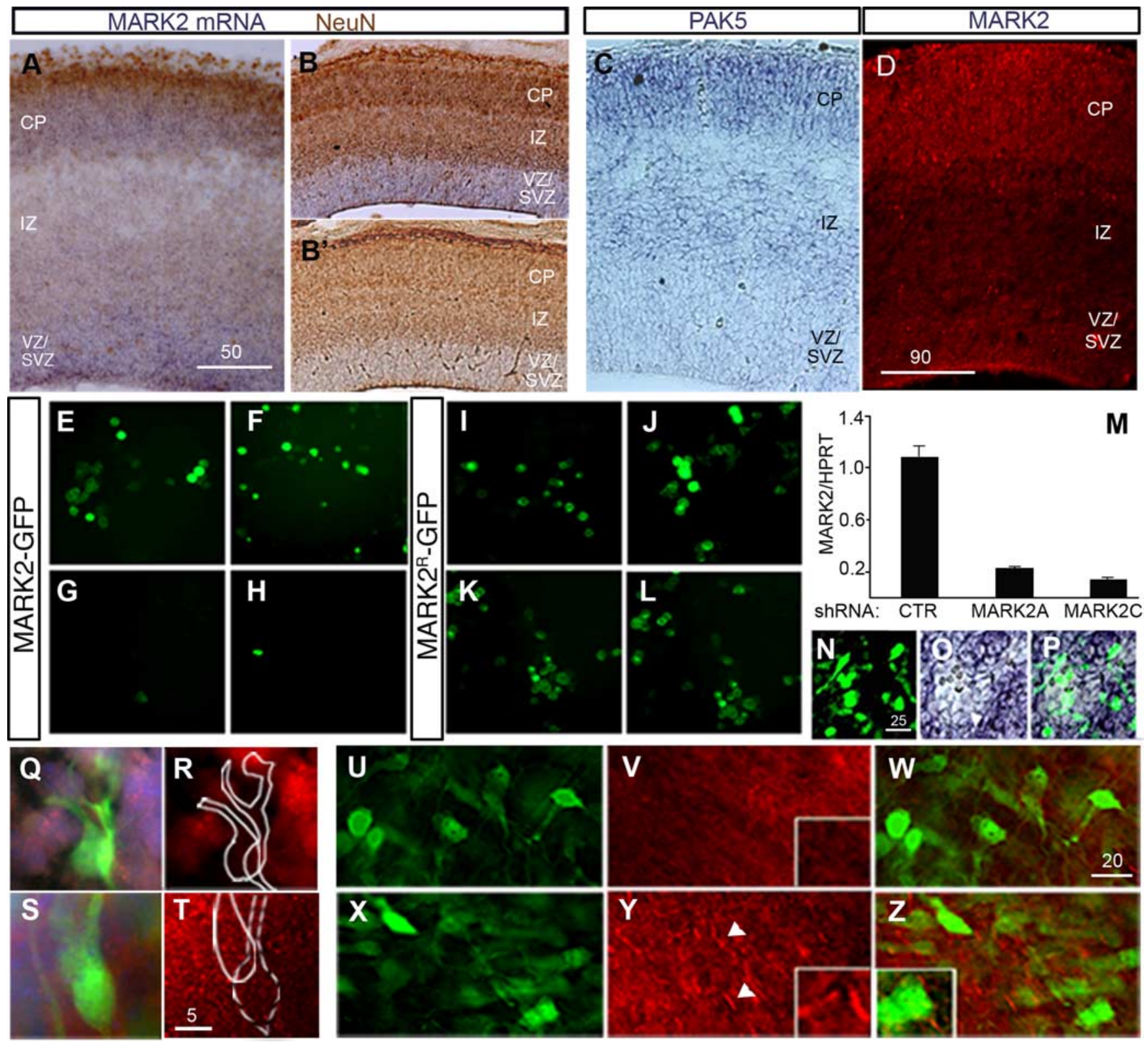

Figure 1. MARK2 is expressed in the developing brain, and its levels can be effectively reduced in vitro and in vivo. $A, B, \boldsymbol{B}^{\prime}$, In situ hybridization of E14 brain sections shows high expression of MARK2 $\mathrm{mRNA}$ in the (P and VZ/SVZ, where NeuN staining is excluded (brown), and lower expression levels in the IZ (A, coronal view; $\boldsymbol{B}$, sagittal view). $\boldsymbol{B}^{\prime}$, No signal was detected using the sense probe. C, PAK5 mRNA is more abundant in the CP and IZ than in the VZ/SVZ of E14 mouse embryos brains. $\boldsymbol{D}$, In E16 brain sections, MARK2 antibodies recognize the protein in locations similar to those at E14; note lower expression levels in the IZ. $E-H$, Exogenous MARK2 expressed as a GFP fusion protein in HEK293 cells was effectively knocked down by two different shRNA sequences, MARK2 shRNAA $(\boldsymbol{G})$ and MARK2 shRNAC $(\boldsymbol{H})$, compared with the GFP-MARK2 expression levels in the presence of a control shRNA plasmid $(\boldsymbol{E}, \boldsymbol{F}), \boldsymbol{I}-\boldsymbol{L}$, Resistance to shRNA of MARK2 WT $(\boldsymbol{I}, \boldsymbol{K})$ and MARK2-KD $(J, L)$ after introduction of silent mutations in the shRNA target site. No reduction in the expression of GFP-MARK $2^{R}(K)$ or GFP-MARK ${ }^{R}$-KD $(\boldsymbol{L})$ was recorded when MARK2 shRNA A was introduced compared with cells expressing control shRNA $(\boldsymbol{I}, \boldsymbol{J}) . \boldsymbol{M}$, Real-time PCR demonstrates reduction in endogenous MARK2 mRNA levels after treatment of differentiated CAD cells with either MARK2 shRNA A or MARK2 shRNA C, whereas cells treated with control shRNA (CTR) continue to exhibit high levels of MARK2 mRNA expression. $\boldsymbol{N}-\boldsymbol{P}$, In situ hybridization of E16 brain slices electroporated in utero with MARK2 shRNA A at E14. A cluster of electroporated cells expressing GFP $(\boldsymbol{N})$ correlates with reduction in MARK2 mRNA signal (0). $\boldsymbol{P}$, Merge of $\boldsymbol{N}$ and $\boldsymbol{O} . \boldsymbol{Q}, \boldsymbol{R}$, Single-cell images taken from electroporated brain slices $2 \mathrm{~d}$ after in utero electroporation of MARK2 shRNA (green cells) show lower MARK2 protein levels by immunostaining with anti-MARK2 antibodies (red) than the untreated cells in the surrounding area (cell nuclei are stained with DAPI, in blue). S, $I$, (ells electroporated with control shRNA (GFP-positive cells in S, cell nuclei in blue) show levels of MARK2 expression (red) similar to those of neighboring cells (note uniform staining in $\boldsymbol{T}$ ). $\boldsymbol{U}-\boldsymbol{Z}$, An area in the SVZ with a cluster of neurons expressing a high concentration of MARK2 shRNA A (shRNA:GFP, 8:1). $\boldsymbol{V}$, The area in $\boldsymbol{U}$ was immunostained with anti-phosphorylated tau (pTau pS262) antibodies (red). The reduction of pTau in the fibers is readily visible. A higher magnification is shown in the boxed inset. $\boldsymbol{W}$, Merge of $\boldsymbol{V}$ and $\boldsymbol{U}$. $\boldsymbol{X}$, Area comparable with that in $\boldsymbol{I}$ from a brain section electroporated in utero with control shRNA and GFP; multiple green neurons are shown. $\boldsymbol{Y}$, The section in $\boldsymbol{X}$ was immunostained with anti-phosphorylated tau (pTau pS262) antibodies (red); immunostaining is obvious mainly in the cell processes and is indicated by the white arrowheads. A higher magnification is shown in the boxed inset. $\boldsymbol{Z}$, Merge of $\boldsymbol{X}$ and $\boldsymbol{Y}$. Scale bar sizes are indicated in micrometers.

MARK2 levels were reduced using previously published shRNA [MARK2 shRNA A (Cohen et al., 2004) or C (Chen et al., 2006)]. The reduction in MARK2 expression was validated using several means. GFP-tagged MARK2 was cotransfected with either MARK2 shRNA or control shRNA plasmid to HEK293 cells, and the reduction in MARK2 was observed by visualization of GFPpositive cells (Fig. $1 E-H$ ). The apparent fluorescence reduction has also been verified by Western blot (supplemental Fig. 1, available at www.jneurosci.org as supplemental material). Using the same system, we validated that either MARK2 or MARK2-KD 


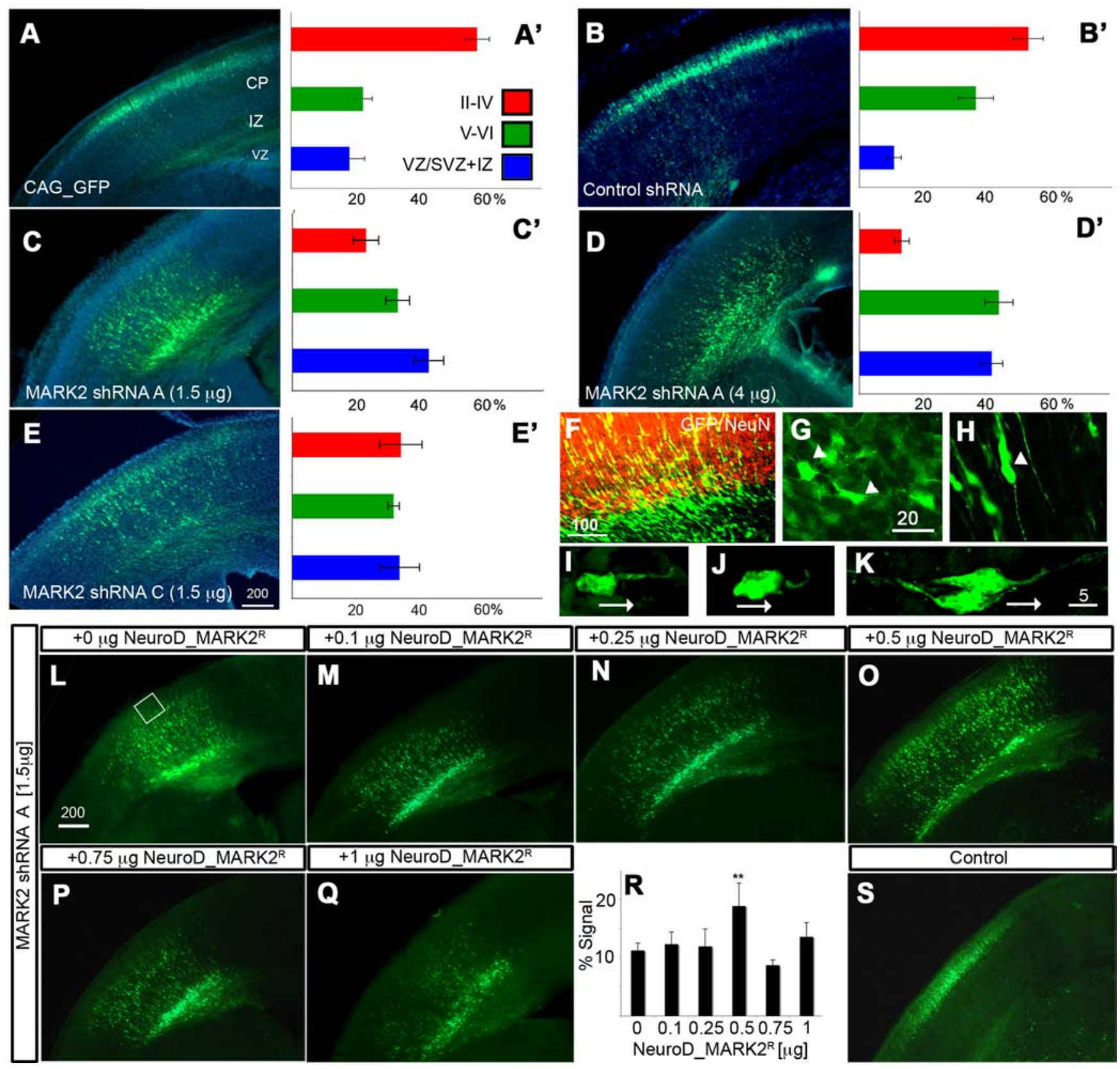

Figure 2. Reduction in MARK2 by in utero electroporation inhibits neuronal migration. $\boldsymbol{A}, \boldsymbol{B}$, Control GFP-labeled neurons $(\boldsymbol{A})$ or control shRNA plasmid cotransfected with GFP $(\boldsymbol{B})$ are preferentially located in the outer layers of the cortical plate (II-IV). The different brain regions marked are VZ, SVZ, IZ, and (P superficial (IIIIV) and deeper (V-VI) layers. A-E, Representative pictures of the indicated shRNA plasmids coelectroporated with GFP. $A^{\prime}-E^{\prime}$, Quantification from sections derived from four different electroporated embryos \pm SE; the shRNA plasmids and the used concentration are indicated in $\boldsymbol{A}-\boldsymbol{E}$. C, Low concentrations of MARK2 shRNA (shRNA A) result in retardation of neuronal migration. $\boldsymbol{D}$, A higher concentration of MARK2 shRNA A results in increased inhibition of neuronal migration. $\boldsymbol{E}$, Low concentrations of a second MARK2 shRNA (shRNAC) inhibit neuronal migration. $\boldsymbol{F}$, Many of the MARK2 shRNA neurons (green cells) are accumulating in the IZ border defined by NeuN immunostaining (red). $\boldsymbol{G}$, Many of the MARK2 shRNA neurons accumulating in the IZ border exhibit multipolar morphology (2 cells are indicated with arrowheads). $\boldsymbol{H}$, Neurons that entered the IZ expressing MARK2 shRNA A exhibited a bipolar structure (white arrowhead). $\boldsymbol{I - K}$, Polarity defects in cells treated with high levels of MARK2 shRNA A. Two cells that exhibit short hooked leading edge are shown $(\boldsymbol{I}, \boldsymbol{J})$. Control cells $(\boldsymbol{H})$ have an elongated leading edge pointing toward the pial surface. Migration direction is indicated by the white arrows. $\boldsymbol{L}-\boldsymbol{S}$, Improvement of neuronal migration inhibition induced by MARK2 shRNA by addition of MARK2 ${ }^{R}$. $L$, Neuronal migration inhibition induced by low concentration of MARK2 shRNA A. $M-Q$, Five different concentrations of NeuroD-MARK2 were introduced together with the same concentration of MARK2 shRNA A. Note the partial rescue in $\boldsymbol{O}$. $\boldsymbol{R}$, Quantification of neurons arriving to the outer surface of the cortical plate (white box in $L$ ) shows significant rescue in the case of $0.5 \mu \mathrm{g}$ of NeuroD-MARK2; the same area was taken from all brain sections (total of 3 brains per experiment). ${ }^{* *} p<$ 0.01. S, Control shRNA with GFP demonstrates that the rescue is partial. Scale bar sizes are indicated in micrometers.

harboring silent mutations within the small interfering RNA sequence were resistant to shRNA A (Fig. $1 I-L)$. These constructs are later referred to as MARK2 ${ }^{\mathrm{R}}$ or MARK $2^{\mathrm{R}}-\mathrm{KD}$. The reduction in endogenous MARK2 RNA levels was demonstrated using realtime RT-PCR (qPCR) (Fig. 1M). A significant reduction in MARK2 RNA levels was observed with either shRNA A or C. In situ hybridization of brain sections electroporated in utero with MARK2 shRNA A demonstrated a convincing reduction in the levels of the endogenous mRNA (Fig. $1 N-P$ ). Furthermore, immunostaining of additional brain sections exhibited reduction in the levels of the endogenous protein (Fig. 1, compare $Q, R$ with $S, T)$. More importantly, the reduction in the levels of endoge- 

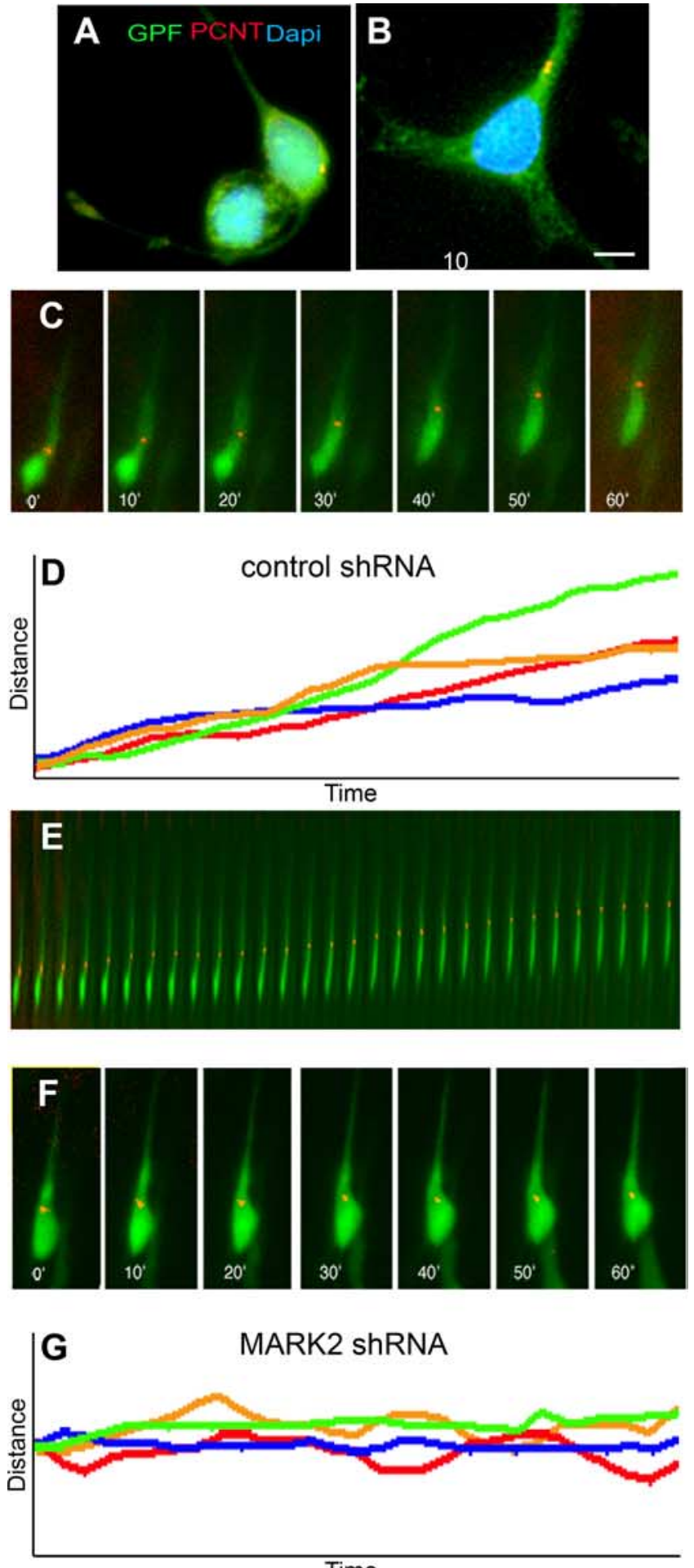

Time

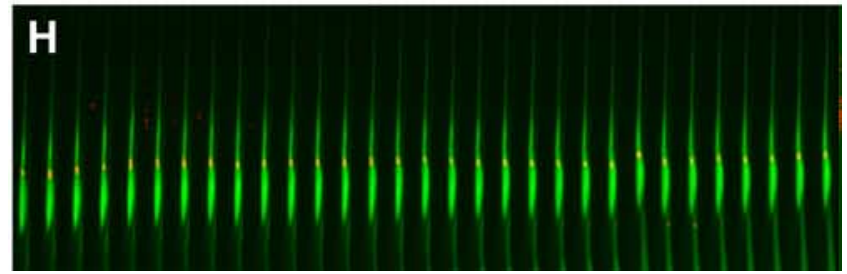

Figure 3. Centrosome-nucleus decoupling and imaging of centrosomal movement in migrating neurons. $\boldsymbol{A}, \boldsymbol{B}$, Hippocampal neurons in dissociated primary cell culture treated with control shRNA ( $\boldsymbol{A})$ or MARK2 shRNA $(\boldsymbol{B})$. A significant increase in centrosome-nucleus distance is noted, whereas in control shRNA-treated cells, the centrosome is localized close to the nucleus [green, GFP-positive neurons; red, immunostaining with pericentrin (PCNT); blue, nuclei nous MARK2 protein was accompanied by functional reduction in MARK2-induced tau phosphorylation at serine 262, which regulates its interaction with microtubules (Drewes et al., 1997) (Fig. 1, compare $V, W$ with $Y, Z$ ). In summary, the above results show widespread expression of MARK2 in the developing brain and document our ability to reduce its levels using shRNA.

Reduction in Par-1/MARK2 affects neuronal migration in the cerebral cortex

Our main experimental method was in utero electroporation, which allows us to preferentially target migrating neurons peaking at E14.5. Because MARK2 is a member of a small family of proteins (Tassan and Le Goff, 2004), in utero electroporation has been shown to circumvent gene redundancy, as previously demonstrated in the case of the Dcx family of proteins (Bai et al., 2003; Koizumi et al., 2006). Reduction of MARK2 levels by in utero electroporation using MARK2 shRNA A or C in the developing mouse brain demonstrated neuronal migration inhibition (Fig. $2 A-E^{\prime}$ ). In control sections (Fig. $1 A, B^{\prime}$ ), the majority of the GFPlabeled neurons reach their proper position in the CP. In all MARK2 shRNA-treated brains, the proportion of neurons reaching the outer layers of CP is markedly reduced (Fig. $2 C-E^{\prime}$ ). The difference between the control and MARK2 shRNA A (both concentrations) is extremely significant $(p=0.0002)$. There was a tendency toward enhanced inhibition using a higher dosage of MARK2 shRNA A. The differences between the control and MARK2 shRNA C were also significant $(p=0.01)$, whereas there were no differences between MARK2 shRNA A and shRNA C. The following studies were conducted using MARK2 shRNA A. The specificity of MARK2 shRNA was further strengthened by a rescue experiment (Fig. $2 I-R$ ). MARK2 shRNA A was electroporated in combination with GFP alone or in addition to increasing concentrations of MARK2 ${ }^{\mathrm{R}}$. MARK $2^{\mathrm{R}}$ expression in this experiment was driven by the neuronal postmitotic promoter NeuroD. The results emphasize the accuracy in which MARK2 levels are required for neuronal migration; only a single concentration among the five tested significantly improved neuronal migration (Fig. 2, compare $L$ with $M-Q$, summarized in $R$ ).

During neuronal migration in the developing cerebral cortex, neurons exiting from the $\mathrm{VZ}$ acquire a multipolar phenotype and later transit to a bipolar morphology in the IZ (Tabata and Nakajima, 2003; Noctor et al., 2004). Importantly, many of the shRNA-treated neurons, which were stalled at the IZ boundary as defined by NeuN-positive immunostaining (Fig. 2F), exhibited multipolar morphology (Fig. $2 G$; cells indicated with white arrowheads exhibit multiple processes). Many neurons are stalled with a multipolar morphology, and a failure in normal radial neuronal migration is suggested. Most of the neurons that reached the CP exhibited bipolar morphology (Fig. $2 H$ ). These

stained with DAPI]. Scale bar size is indicated in micrometers. $\mathbf{C} \boldsymbol{H}$, Time-lapse images taken from organotypic slice cultures from brain electroporated in utero reveal centrosomal movement during the course of $1 \mathrm{~h} . \boldsymbol{C}, \boldsymbol{D}$, Cell treated with control shRNA in utero continued to migrate in the slice. $\boldsymbol{C}$, Images extracted from the movies every $10 \mathrm{~min}$. The movement of the centrosome is continuous. In all images, centrosomes are labeled with centrin-dsRed, and the cells are labeled with GFP. D, Tracking the movement of four cells during the course of $1 \mathrm{~h}$ shows linear progression of all of their centrosomes. $\boldsymbol{E}$, Kymograph of the same cell as in $\boldsymbol{C}$ presenting the centrosome continuous movement as the cell migrates. $\boldsymbol{F}-\boldsymbol{H}$, A cell treated with MARK2 shRNA shows inhibition in centrosomal movement and cellular motility. $\boldsymbol{F}$, Time-lapse images of MARK2 shRNA-treated cell. $\mathbf{G}$, Tracking the movement of four centrosomes in MARK2 shRNAtreated cells shows oscillations and failure to advance in the direction of migration. $\boldsymbol{H}$, Images of a representative cell treated with MARK 2 shRNA, taken every 2 min in the course of $1 \mathrm{~h}$. 
different morphologies normally occur during the route of radial neuronal migration. In vivo, especially when using MARK2 shRNA at higher concentrations, some of the neurons exhibited morphologies, which are not observed in control neurons. Neurons that passed the IZ border had a curved leading edge (Fig. 2, compare $I, J$ with $K)$. In conclusion, neurons with reduced MARK2 levels in vivo and hindered migration mostly display multipolar morphology.

Collectively, our results show that reduction in MARK2 levels impairs neuronal migration, which is partially rescued by addition of accurate amounts of MARK $2^{\mathrm{R}}$. After reduction of MARK2, neurons are typically stalled in a premature multipolar morphology at the border of the IZ, thus implicating that the temporal and spatial expression of MARK2 is important for regulation of neuronal migration.

\section{Reduction in MARK2 affects} the centrosome

Less efficient coupling of the centrosome and the nucleus is known to be associated with reduced neuronal migration (Xie et al., 2003; Shu et al., 2004; Solecki et al., 2004; Tanaka et al., 2004; Tsai and Gleeson, 2005; Asada et al., 2007; Tsai et al., 2007). Significantly, MARK2 may affect the centrosome through its activity as a polarity regulator. Moreover, reduction of MARK2 in hippocampal neurons in dissociated primary cell culture has been shown to result in multiple axons (Chen et al., 2006). To first test whether reduction in MARK2 can affect the position of the centrosome in hippocampal neurons in dissociated primary cell culture, we transfected neurons with control shRNA or MARK2 shRNA. Reduction in MARK2 increased the average distance between the centrosome and the nucleus (Fig. $3 A, B$ ). The distance between the centrosome and the nucleus at reduced MARK2 levels was $3.5 \pm 0.4 \mu \mathrm{m}$, whereas in control transfected hippocampal neurons it was 2.5 -fold less $(1.37 \pm 0.16$ $\mu \mathrm{m} ; p<0.0001 ; n=60)$.

Next, we monitored the dynamic behavior of the centrosome in migrating neurons in vivo. Using time-lapse movies, we show that in vivo control centrosomes move continuously in a forward direction (Fig. $3 C-E$; supplemental Movie 1 $a, b$, available at www.jneurosci.org as supplemental material), as previously reported (Tsai et al., 2007). For these experiments, embryos were coelectroporated in utero with centrin-RFP (to label the centrosome), GFP (to label the cell), and the additional indicated shRNA plasmids. On the third day after electroporation, brains were excised, sectioned, and plated on inserts to follow centrosome motility using timelapse microscopy. At this stage, a large proportion of neurons are migrating in control brains. MARK2 reduction resulted in slow
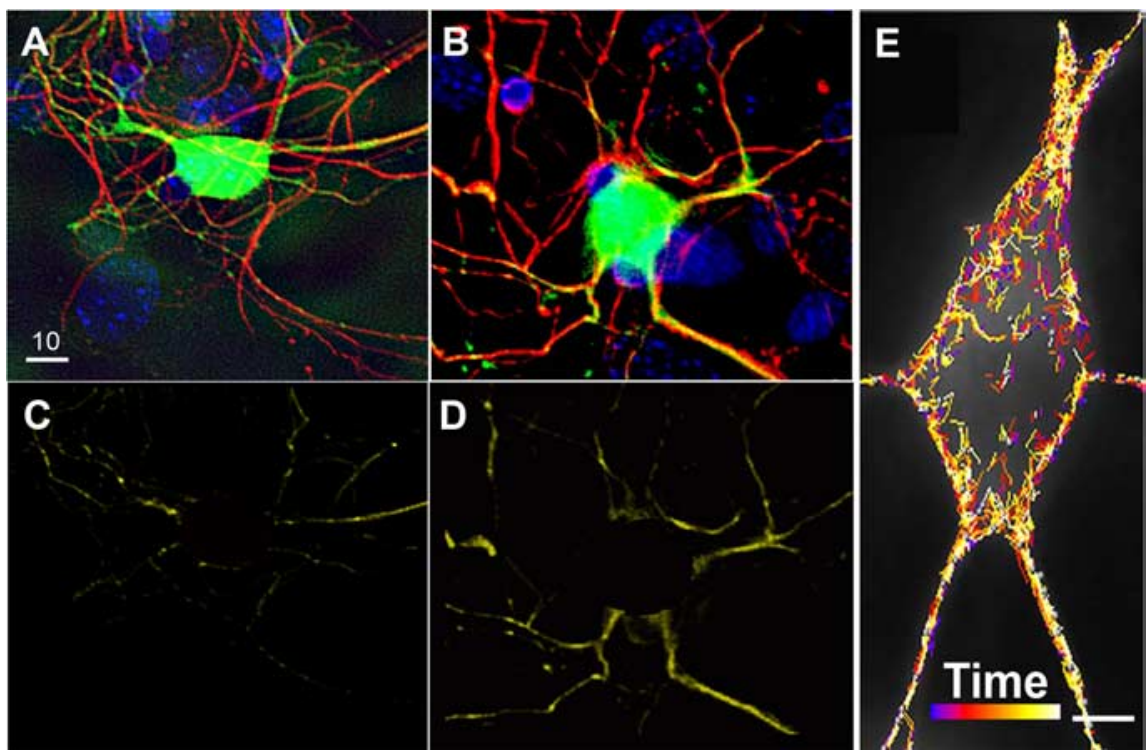

Figure 4. Reduction in MARK2 affects microtubule dynamics. $A, B$, Stabilization of microtubules in hippocampal neurons in dissociated primary cell culture treated with MARK2 shRNA A. Processes of a GFP + control shRNA-treated cell $(\boldsymbol{A})$ show some costaining with anti-detyrosinated $\alpha$-tubulin antibodies (red). This colocalization becomes more prominent when cells are treated with MARK2 shRNA A (note the yellow neuronal extensions in $\boldsymbol{B}$ ). $\boldsymbol{C}, \boldsymbol{D}$, Colocalization of transfected neurites with anti-detyrosinated $\alpha$-tubulin immunostaining using SoftWoRx colocalization tool. Nuclear area has been removed. $E$, Hippocampal neurons in dissociated primary cell culture transfected with shRNA-containing plasmids and EB3-GFP were tracked using an Imaris cell-tracking system. A representative neuron is shown in $E$; the lines shown in different colors are marking the advance of individual tracks over time measured by the program. Earlier time points are in blue, and the final ones are in white (color-coded time bar is shown). Scale bars: (in $\boldsymbol{A}) \boldsymbol{A}-\boldsymbol{D}, 10 \mu \mathrm{m} ; \boldsymbol{E}, 5 \mu \mathrm{m}$.
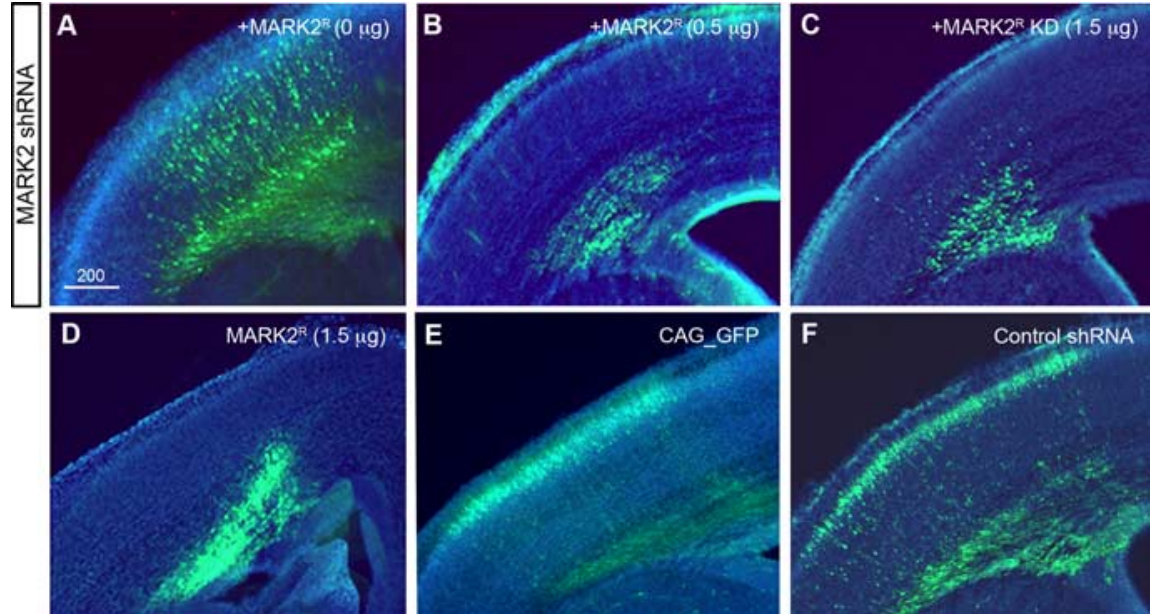

Figure 5. Dissecting the role of MARK2 in the developing cortex using MARK2 shRNA, MARK2 ${ }^{R}$, and MARK2 ${ }^{R}-K D . A-C$, Expression of low levels of MARK2 shRNA inhibits neuronal migration $(\boldsymbol{A})$; further addition of active $\operatorname{MARK}^{\mathrm{R}}(\boldsymbol{B})$ or inactive MARK2 ${ }^{R}-K D(C)$ did not rescue the migration phenotype. $\boldsymbol{D}$, Expression of MARK $2^{\mathrm{R}}$ results in a severe phenotype. $\boldsymbol{E}, \boldsymbol{F}$, Normal neuronal migration is observed using GFP $(\boldsymbol{E})$ or GFP combined with control shRNA $(\boldsymbol{F})$. Scale bar size is indicated in micrometers.

and often nonoriented motility of the centrosome (Fig. 3F-H; supplemental Movie 2a, $b$, available at www.jneurosci.org as supplemental material).

At least 15 different cells from each treatment were subjected to more detailed analysis. The average velocity of MARK2 shRNA-treated centrosomes was significantly lower than the control group $\left(15.56 \pm 1\right.$ vs $\left.24.23 \pm 2 \mu \mathrm{m} \cdot \mathrm{h}^{-1}\right)$. The mean velocity of the control centrosomes fits very well with previously published measurements of migrating neurons (Fishell and Hatten, 1991; Rio et al., 1997; Bovetti et al., 2007). Our results indicate that reduction in MARK2 affects centrosomal behavior both 


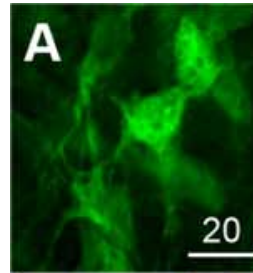

\section{C}
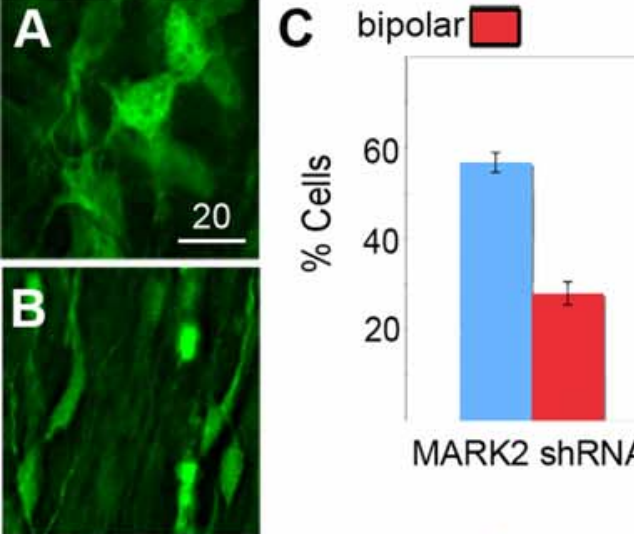

multipolar
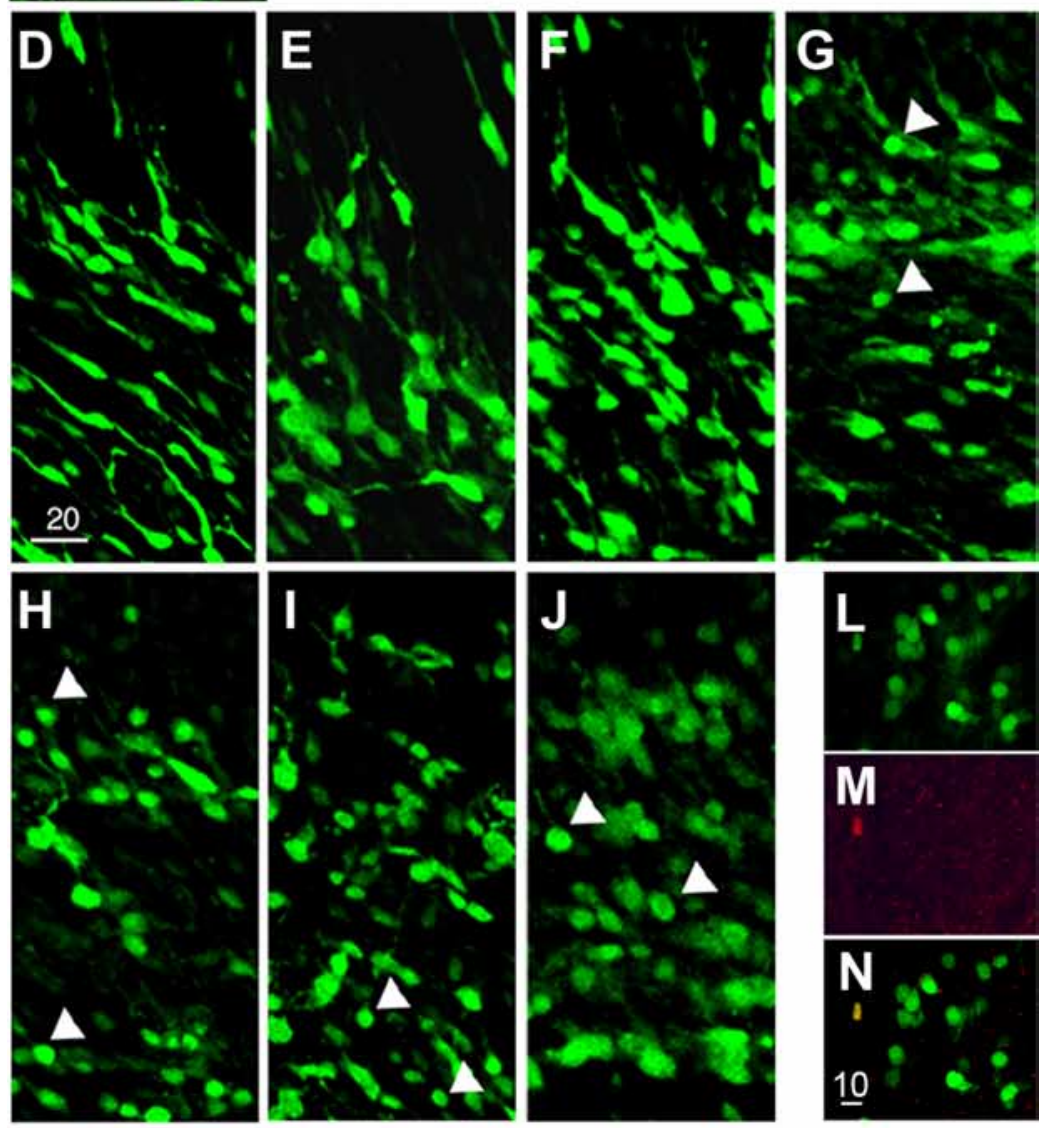

$\mathbf{K}$

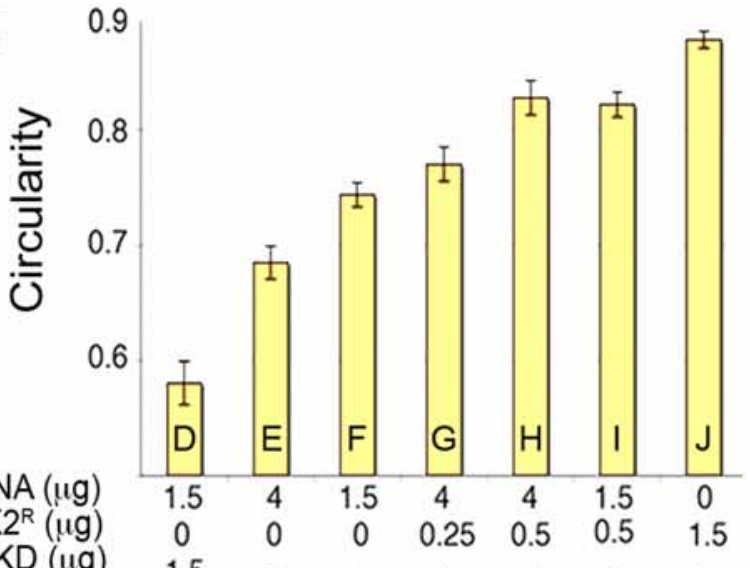

shRNA ( $\mu \mathrm{g})$

$\operatorname{MARK}^{R}(\mu \mathrm{g})$ MARK2R KD $(\mu \mathrm{g})$

Figure 6. Deregulation of MARK2 levels causes loss of polarity in migrating neurons. $A-C$, Multipolar cells $(\boldsymbol{A})$ stalled at the IZ boundary of MARK2 RNA A-treated brains resume bipolar morphology when MARK2 ${ }^{\mathrm{R}}$-KD is introduced in addition to MARK2 shRNA (B). C, Histogram representing the proportion of each cellular morphology after

in hippocampal neurons in dissociated primary cell culture and in cortical neurons migrating in the cerebral cortex. Reduction in centrosomal motility may be one of the reasons underlying inhibited neuronal migration in vivo.

\section{Reduction in MARK2 affects}

microtubule dynamics

We suggested that MARK2 may affect neuronal migration through regulation of microtubule dynamics, because increased MARK2 expression resulted in less stable microtubules because of the removal of phosphorylated MAPs (Biernat et al., 2002; Timm et al., 2003; Matenia et al., 2005). Therefore, we hypothesized that reduced MARK2 will result in more stable microtubules. This hypothesis was tested first by immunostaining of transfected hippocampal neurons in dissociated primary cell culture with anti-detyrosinated $\alpha$-tubulin antibodies (Fig. $4 A, B$ ). The immunostaining for the marker of stabilized microtubules was increased in the neurites of neurons transfected with MARK2 shRNA in comparison with control shRNA [Fig. 4, compare $B$ with $A$; the colocalization within the neurites of the transfected cells after threshold subtraction is shown as well (compare $D$ with $C$ )]. The difference between the control and the MARK2 shRNAtreated neurons of the Pearson coefficient of the correlation (see Materials and Methods) assayed by Student's $t$ test was statistically significant $(p=$ 0.0098 ; mean \pm SEM of control, $0.05748 \pm$ $0.02792 ; n=4$; mean \pm SEM of MARK2 shRNAtreated cells, $0.1762 \pm 0.02234 ; n=7)$. Next we examined microtubules dynamics via tracking the duration of EB3-GFP on tips of microtubules (Fig. $4 E)$. Each track in the EB3 movie is coded by a rainbow color that represents time. Hippocampal neurons in dissociated primary cell culture were transfected with either control shRNA or MARK2 shRNA. Neurons transfected with MARK2 shRNA exhibited more stable microtubules as longer durations of EB3 on the microtubule plus-ends were measured (means \pm SEM control, $36.82 \pm 0.57 \mathrm{~s}$; MARK2 shRNA-treated cells, $42.59 \pm 0.918 \mathrm{~s}$; control, $n=8$ cells, 11,375 tracks; MARK2 shRNA, $n=$ 6 cells, 5222 tracks; statistical analysis by Student's $t$

\section{$\leftarrow$}

treatment with MARK2 shRNA A in the absence and presence of MARK $2^{\mathrm{R}}$ KD. $\boldsymbol{D}-\boldsymbol{J}$, Images from in utero electroporated brain sections expressing MARK2 shRNA A and $\operatorname{MARK} 2^{\mathrm{R}}(\boldsymbol{D})$, MARK2 shRNA A ( 4 or $1.5 \mu \mathrm{g} ; \boldsymbol{E}, \boldsymbol{F}$ ), and increasing levels of MARK2 ${ }^{R}(\mathbf{G}-J): 4 \mu \mathrm{g}$ of MARK2 shRNA and 0.25 or 0.5 $\mu \mathrm{g}$ of $\operatorname{MARK} 2^{\mathrm{R}}(\boldsymbol{G}, \boldsymbol{H}), 1.5 \mu \mathrm{g}$ of MARK2 shRNA A and $0.5 \mu \mathrm{g}$ of MARK2 ${ }^{\mathrm{R}}$ $(I)$, and $1.5 \mu \mathrm{g}$ of MARK $2^{\mathrm{R}}(\boldsymbol{J}) . \boldsymbol{K}$, The cells from $\boldsymbol{D}$ - $J$ were plotted, and the circularity index was measured using the ImageJ program (for details, see Materials and Methods). $\mathbf{L}-\mathbf{N}$, A confocal image of a section from a MARK2 ${ }^{R}$-treated brain. This experiment includes $1.5 \mu \mathrm{g}$ of shRNA and 0.5 $\mu \mathrm{g}$ of MARK $2^{\mathrm{R}}$. $L$, Most of the rounded cells are not positive for cleaved caspase-3 (red staining; Asp 175; (ell Signaling). $\boldsymbol{M}$, One cell in the field shows a positive staining. $\boldsymbol{N}$, Merged image of $\boldsymbol{L}$ and $\boldsymbol{M}$. Our statistical analysis suggested that this image faithfully represents the observed rate of apoptosis after electroporation of MARK2 ${ }^{R}$. Scale bar sizes are indicated in micrometers. 


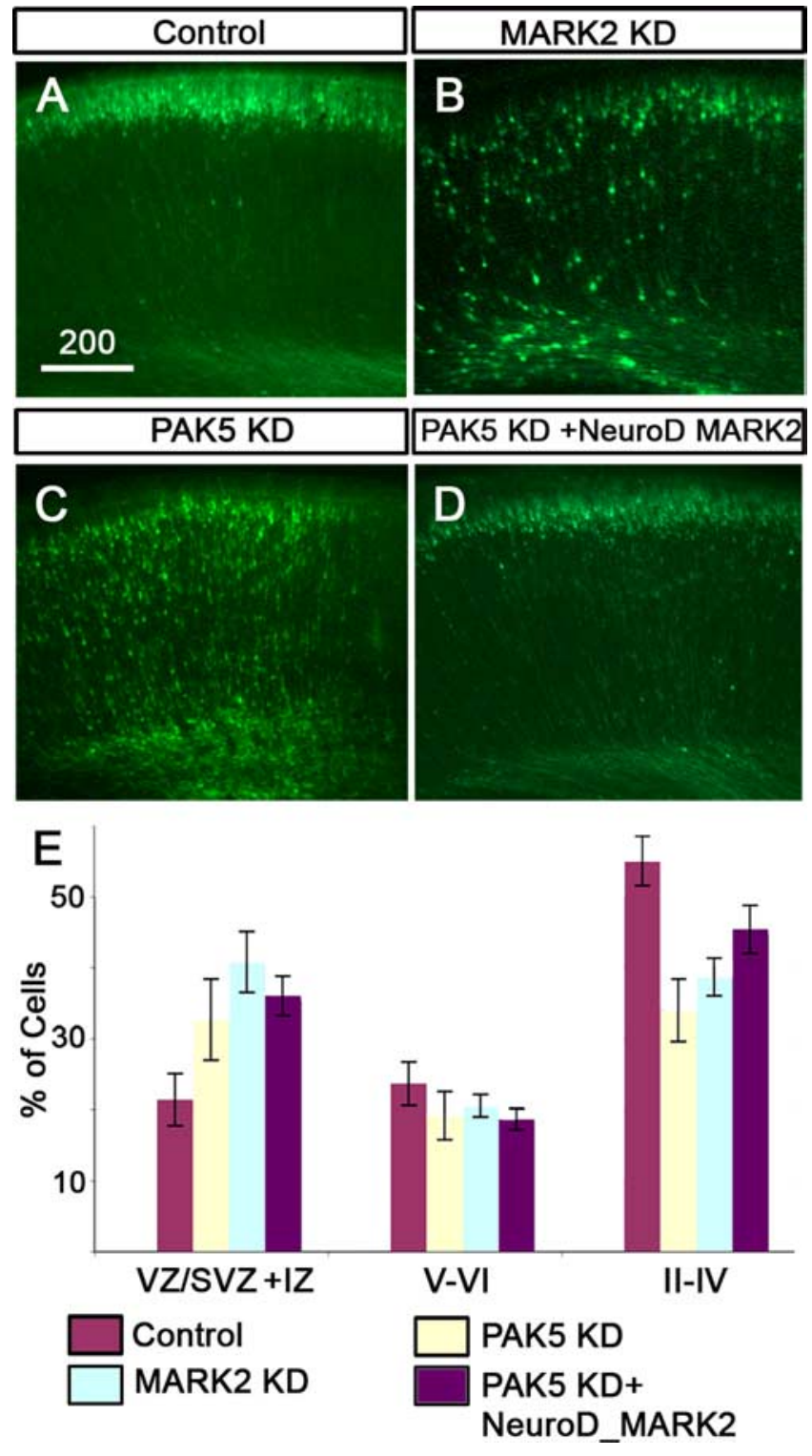

Figure 7. Reduction in MARK2 kinase activity inhibits neuronal migration. $\boldsymbol{A}$, Transfection of a control GFP plasmid does not affect the normal migration of neurons. $\boldsymbol{B}$, Overexpression of MARK $2^{R}-K D$ results in a reduction of neuronal migration. $C$, 0 verexpression of PAK5-KD inhibits neuronal migration. $\boldsymbol{D}$, Addition of NeuroD-MARK2 to PAK5-KD facilitates neuronal migration (does not statistically differ from control). Thus, MARK2 kinase activity is strongly implicated in regulation of neuronal migration. $\boldsymbol{E}$, Quantification of all the above experiments from four brains \pm SE. Scale bar size is indicated in micrometers.

test, $p<0.001)$. On the other hand, an inverse correlation was noted for the rate of microtubule polymerization; microtubules polymerized slower in the absence of MARK2 (mean \pm SEM control, $4.09 \mu \mathrm{m} / \mathrm{min} \pm 0.026$; MARK2 shRNA-treated cells, $3.7 \pm 0.036 \mu \mathrm{m} / \mathrm{min}$; statistical analysis by Student's $t$ test, $p<$ $0.001)$. The rate of microtubule polymerization correlates well with previously reported rates (Stepanova et al., 2003; Tsai et al., 2007). Together, the data are consistent with altered microtubule growth and stability, indicating that MARK2 may be an important regulator of microtubule dynamics.

\section{Kinase-dependent and kinase-independent activities of MARK2}

The complex morphological transformations that a migrating neuron undergoes are subject to intricate regulatory mecha- nisms. Based on the above results, we hypothesized that regulation of MARK2 protein concentration and/or its kinase activity may be important factors in this process. To distinguish between the relative contributions of the MARK2 protein and its kinase activity, we used several combinations of MARK2 expression, specifically the MARK2 shRNA-resistant either wild-type active kinase $\left(\mathrm{MARK} 2^{\mathrm{R}}\right)$ or $\mathrm{KD}\left(\mathrm{MARK} 2^{\mathrm{R}}-\mathrm{KD}\right)$, with or without MARK2 shRNA. Unexpectedly, partial rescue of the MARK2 shRNA phenotype was also observed with addition of MARK2 ${ }^{\mathrm{R}}$ KD. Two features were noted: first, the typical accumulation of multipolar cells at the IZ boundary in the presence of MARK2 shRNA was alleviated (Fig. 5, compare $C$ with $A$ ). Second, neurons managed to attain the elongated morphology usually observed in migrating neurons (discussed below). In all cases in which MARK $2{ }^{\mathrm{R}}$ was expressed under the $\mathrm{CAG}$ promoter, both in the presence or absence of MARK2 shRNA, cells failed to escape the IZ (Fig. 5, compare B,D with $E, F$ ) and did not migrate to their proper position. These results suggested that increased kinase activity at early stages is not compatible with progression of neuronal migration.

As noted above, when MARK2 ${ }^{\mathrm{R}}-\mathrm{KD}$ was added to MARK2 shRNA, a striking morphological change was noted. Cells exhibiting multipolar (Fig. $6 A$ ) or bipolar (Fig. $6 B$ ) morphologies were counted (Fig. $6 C$ ) in sections treated either with MARK2 shRNA or with MARK2 shRNA and MARK2 ${ }^{\mathrm{R}}-\mathrm{KD}$. In the presence of MARK2 shRNA, $56.8 \pm 2.1 \%$ of the cells exhibited multipolar morphology. Noticeably, addition of MARK $2^{\mathrm{R}}-\mathrm{KD}$ reduced the level of multipolar cells by 4.75 -fold to $11.9 \pm 2.3 \%$. The relative ratio of bipolar cells increased dramatically (2.6-fold) from $28 \pm$ 2.8 to $73.6 \pm 1.9 \%$. Despite the rescue of cell morphology, the migration distance was not corrected in the presence of the kinase-dead mutant (Fig. 5C). This result is consistent with our findings that precise kinase activity is required for proper neuronal migration.

When MARK2 ${ }^{\mathrm{R}}$ was added to MARK2 shRNA, many of the inhibited cells exhibited a round structure, accompanied by loss of extensions and polarity (Fig. 6G-J, white arrows). The vast majority of these round cells were not apoptotic as determined by anti-activated caspase-3 immunostaining (89\% of 807 cells, counted from 10 different sections) (Fig. $6 \mathrm{~L}-\mathrm{N}$ ). Loss of polarity was dose dependent; incremental additions of active MARK2 correlated with an increased measured circularity index (Fig. $6 \mathrm{~K}$ and Materials and Methods). The lowest levels of MARK2 activity were achieved by combining the reduction of the levels of the endogenous kinase with addition of MARK2-kinase dead, which further decreased the levels of remaining endogenous MARK2 activity. This is followed by high or low levels of MARK2 shRNA later combined with low or moderate levels of wild-type MARK $2^{\mathrm{R}}$. The last in this series, high levels of wild-type MARK2, resulted in the maximal circularity index. Collectively, these results suggest that increasing MARK2 kinase activity early is detrimental for neuronal polarity. Moreover, the MARK2 protein, independent of its kinase activity, allows for transition from the multipolar to a bipolar morphology.

Expression of inactive MARK $2^{\mathrm{R}}-\mathrm{KD}$ did not rescue the migration phenotype, because the majority of cells did not reach their proper position in the $\mathrm{CP}$ (Fig. $5 \mathrm{C}$ ). As noted above, when MARK2 ${ }^{\mathrm{R}}$-KD was expressed, neurons assumed the bipolar morphology (Fig. $6 B, D$ ), and this phenotype differed from the phenotype that was observed in the case of expressing MARK2 shRNA alone (Fig. 6A,E,F). Therefore, our results indicate that tightly regulated MARK2 activity is essential for neuronal migration. 
MARK2 kinase activity is required for proper neuronal motility and migration Next, the importance of kinase activity in migrating neurons was assayed using two means to modulate MARK2-kinase activity. The MARK2 kinase-dead mutant exhibits dominant-negative properties, consistent with a mechanism whereby dimerization with the endogenous MARK2 and/or sequestering of upstream kinases results in reduced kinase activity (Panneerselvam et al., 2006). Expression of MARK $2^{\mathrm{R}}-\mathrm{KD}$ in the absence of MARK2 shRNA resulted in a moderate retardation of neuronal migration ( $p=0.02$ ) (Fig. 7 , compare $B$ with $A$, quantified in $E$ ). These results suggest that regulated kinase activity is required for migration of neurons to their proper position in the CP. Additional experiments support the same conclusion. For example, the kinase activity is reduced by other means, such as expression of PAK5, which has been shown to bind to the catalytic domain of MARK2, and thereby inhibit its enzymatic activity (Matenia et al., 2005). Because PAK5 kinase activity is not required for this inhibition and because PAK5 enzymatic activity is known to affect the actin cytoskeleton, we have used a kinase-dead version (PAK5-KD). Overexpression of PAK5-KD inhibited in vivo neuronal migration $(p=0.002)$ (Fig. $7 C$ ) to an extent similar to that observed with expression of MARK $2^{\mathrm{R}}$-KD (Fig. 7E). The impairment of neuronal migration resulting from kinase reduction was corrected when NeuroD-MARK2 was introduced at a specific concentration (Fig. $7 D, E$ ). The observed correction further emphasized that reduction in MARK2 kinase activity hampers neuronal migration. Together, the above results implicate the importance of MARK2 kinase activity in radial neuronal migration.

\section{Discussion}

Our main experimental method was in utero electroporation, which allowed us to preferentially target migrating neurons peaking at E14.5. Furthermore, because MARK2 is a member of a small family of proteins (Tassan and Le Goff, 2004), in utero electroporation has been shown to circumvent gene redundancy, as previously demonstrated in the case of the Dcx family of proteins (Bai et al., 2003; Koizumi et al., 2006). Therefore, although cortical abnormalities have not been reported in MARK2 mutant mice (Bessone et al., 1999), and have not been detected in DCXdeficient mice (Corbo et al., 2002), acute reduction has allowed us to distinguish the unique functions of these proteins in radially migrating cortical neurons. This technique has also been useful to resolve between cell autonomous and non-cell-autonomous features of mutants that do display a migration phenotype and also to further reduce levels of proteins where the homozygote mice are lethal. Two examples for these issues are acute reduction of LIS1 (Shu et al., 2004; Tsai et al., 2005, 2007) and expression of dominant-negative Cdk5 (Ohshima et al., 2007). MARK2 regulates several steps of neuronal migration via kinase-independent and kinase-dependent activities, as summarized in our model (Fig. 8). Our results indicate that MARK2 enzymatic activity is necessary for proper neuronal migration in vivo (Fig. 8, compare $B, D$ with $A$ ). A dose-dependent rescue was observed with introduction of accurate amounts of MARK2 postmitotically using the NeuroD promoter (Fig. $8 C$ ). Elevating MARK2 kinase activity resulted in a dosage-specific loss of polarity and inhibition of neuronal migration (Fig. $8 E$ ). Ectopic expression of the kinase, which can also result in mislocalization of the endogenous kinase, might be the underlying cause for polarity loss. In the case of reduced MARK2 levels, neurons are stalled mainly in a multipolar manner, and some of the stalled neurons exhibited abnormal morphology (Fig. 8B). Addition of MARK2-KD allowed transition from the multipolar to bipolar stage, but did not rescue the migration phenotype (Fig. 8D), further suggesting that regulated kinase activity is also necessary for neuronal migration. Timelapse movies (not shown) suggest that the multipolar cells are not static, because they are actively sending multipolar extensions; however, they fail to become bipolar. These results may also stem from a possible effect of MARK2 on cell adhesion. Previous experiments in MDCK cells suggest that MARK2 directly affects cadherins, which impact cell adhesive properties (Elbert et al., 2006; Cohen et al., 2007). Cdk5 directly interacts with $\mathrm{N}$-cadherin, and this interaction may play an important role in the abnormal neuronal migration phenotype observed in the Cdk5-/- or p35-/- mice (Kwon et al., 2000). Therefore, it may be hypothesized that intruding cell-cell interaction plays a role in the observed phenotype. Our studies provided a direct visualization of basic mechanisms involved in stalled multipolar neurons with reduced MARK2. Centrosomes in radially migrating cortical neurons usually move in a continuous manner, and the cell body follows (Tsai et al., 2007) (Fig. 8 A, red dot). Reduc- 
tion of MARK2, as we have shown with more stable microtubules, results in a centrosome that is not very motile (Fig. $8 \mathrm{~B}$ ). These results stress the significance of processive centrosomal motility during successful neuronal migration.

Regulating the transition between the multipolar to the bipolar stage is a new and unpredicted role of MARK2, and may be attributed to its putative protein scaffolding activities. Several in utero experiments have revealed a role for LIS1 (Tsai et al., 2005), DCX (Bai et al., 2003), CDK5 (Ohshima et al., 2007), and Filamin A (Flna) (Nagano et al., 2002, 2004) in the regulation of the multipolar stage. Here, we have shown two means to rescue neurons stalled in the multipolar stage. The first is by addition of the postmitotic MARK2, which at a specific concentration rescued neuronal migration. This experiment controlled for the specificity of the introduced shRNA. The second was by introduction of the kinase-dead mutant of MARK2, which allowed for the morphological change but failed to correct the migration inhibition.

MARK2 kinase activity is further required in the progression of radially migrating neurons. Overexpression of PAK5-KD or MARK2-KD, both of which inhibit MARK2 kinase activity, moderately inhibited neuronal migration. Neurons were stalled in the course of their migration to the CP (Fig. 8 C). This phenotype was corrected when NeuroD-MARK2 was introduced on top of PAK5-KD. The kinase activity during neuronal migration is reflected by the phosphorylation of its substrates, and their subsequent change in action. The above results raised the issue of the importance of different MARK2 substrates during radial neuronal migration. These findings assist in dissection and definition of the multiple required steps, whose coordination leads to successful neuronal migration. Our results suggest that MARK2/Par-1 plays important regulatory roles during cortical development.

\section{References}

Asada N, Sanada K, Fukada Y (2007) LKB1 regulates neuronal migration and neuronal differentiation in the developing neocortex through centrosomal positioning. J Neurosci 27:11769-11775.

Bai J, Ramos RL, Ackman JB, Thomas AM, Lee RV, LoTurco JJ (2003) RNAi reveals doublecortin is required for radial migration in rat neocortex. Nat Neurosci 6:1277-1283.

Barnes AP, Lilley BN, Pan YA, Plummer LJ, Powell AW, Raines AN, Sanes JR, Polleux F (2007) LKB1 and SAD kinases define a pathway required for the polarization of cortical neurons. Cell 129:549-563.

Bessone S, Vidal F, Le Bouc Y, Epelbaum J, Bluet-Pajot MT, Darmon M (1999) EMK protein kinase-null mice: dwarfism and hypofertility associated with alterations in the somatotrope and prolactin pathways. Dev Biol 214:87-101.

Biernat J, Wu YZ, Timm T, Zheng-Fischhofer Q, Mandelkow E, Meijer L, Mandelkow EM (2002) Protein kinase MARK/PAR-1 is required for neurite outgrowth and establishment of neuronal polarity. Mol Biol Cell 13:4013-4028.

Bovetti S, Bovolin P, Perroteau I, Puche AC (2007) Subventricular zonederived neuroblast migration to the olfactory bulb is modulated by matrix remodelling. Eur J Neurosci 25:2021-2033.

Brann AB, Tcherpakov M, Williams IM, Futerman AH, Fainzilber M (2002) Nerve growth factor-induced p75-mediated death of cultured hippocampal neurons is age-dependent and transduced through ceramide generated by neutral sphingomyelinase. J Biol Chem 277:9812-9818.

Brummelkamp TR, Bernards R, Agami R (2002) A system for stable expression of short interfering RNAs in mammalian cells. Science 296:550-553.

Chen YM, Wang QJ, Hu HS, Yu PC, Zhu J, Drewes G, Piwnica-Worms H, Luo ZG (2006) Microtubule affinity-regulating kinase 2 functions downstream of the PAR-3/PAR-6/atypical PKC complex in regulating hippocampal neuronal polarity. Proc Natl Acad Sci USA 103:8534-8539.

Chin JY, Knowles RB, Schneider A, Drewes G, Mandelkow EM, Hyman BT (2000) Microtubule-affinity regulating kinase (MARK) is tightly associated with neurofibrillary tangles in Alzheimer brain: a fluorescence resonance energy transfer study. J Neuropathol Exp Neurol 59:966-971.

Cohen D, Brennwald PJ, Rodriguez-Boulan E, Musch A (2004) Mammalian
PAR-1 determines epithelial lumen polarity by organizing the microtubule cytoskeleton. J Cell Biol 164:717-727.

Cohen D, Tian Y, Musch A (2007) Parlb promotes hepatic-type lumen polarity in Madin Darby canine kidney cells via myosin II- and E-cadherindependent signaling. Mol Biol Cell 18:2203-2215.

Corbo JC, Deuel TA, Long JM, LaPorte P, Tsai E, Wynshaw-Boris A, Walsh CA (2002) Doublecortin is required in mice for lamination of the hippocampus but not the neocortex. J Neurosci 22:7548-7557.

de Anda FC, Pollarolo G, Da Silva JS, Camoletto PG, Feiguin F, Dotti CG (2005) Centrosome localization determines neuronal polarity. Nature 436:704-708

Drewes G, Ebneth A, Preuss U, Mandelkow EM, Mandelkow E (1997) MARK, a novel family of protein kinases that phosphorylate microtubuleassociated proteins and trigger microtubule disruption. Cell 89:297-308.

Drewes G, Ebneth A, Mandelkow EM (1998) MAPs, MARKs and microtubule dynamics. Trends Biochem Sci 23:307-311.

Elbert M, Cohen D, Musch A (2006) PAR1b promotes cell-cell adhesion and inhibits dishevelled-mediated transformation of Madin-Darby canine kidney cells. Mol Biol Cell 17:3345-3355.

Fishell G, Hatten ME (1991) Astrotactin provides a receptor system for CNS neuronal migration. Development 113:755-765.

Govek EE, Newey SE, Van Aelst L (2005) The role of the Rho GTPases in neuronal development. Genes Dev 19:1-49.

Kawai J, Hayashizaki Y (2003) DNA book. Genome Res 13:1488-1495.

Kishi M, Pan YA, Crump JG, Sanes JR (2005) Mammalian SAD kinases are required for neuronal polarization. Science 307:929-932.

Koizumi H, Tanaka T, Gleeson JG (2006) Doublecortin-like kinase functions with doublecortin to mediate fiber tract decussation and neuronal migration. Neuron 49:55-66.

Kwon YT, Gupta A, Zhou Y, Nikolic M, Tsai LH (2000) Regulation of $\mathrm{N}$-cadherin-mediated adhesion by the p35-Cdk5 kinase. Curr Biol 10:363-372.

Macara IG (2004) Parsing the polarity code. Nat Rev Mol Cell Biol 5:220-231.

Matenia D, Griesshaber B, Li XY, Thiessen A, Johne C, Jiao J, Mandelkow E, Mandelkow EM (2005) PAK5 kinase is an inhibitor of MARK/Par-1, which leads to stable microtubules and dynamic actin. Mol Biol Cell 16:4410-4422.

Nagano T, Yoneda T, Hatanaka Y, Kubota C, Murakami F, Sato M (2002) Filamin A-interacting protein (FILIP) regulates cortical cell migration out of the ventricular zone. Nat Cell Biol 4:495-501.

Nagano T, Morikubo S, Sato M (2004) Filamin A and FILIP (Filamin A-interacting protein) regulate cell polarity and motility in neocortical subventricular and intermediate zones during radial migration. J Neurosci 24:9648-9657.

Nishimura I, Yang Y, Lu B (2004) PAR-1 kinase plays an initiator role in a temporally ordered phosphorylation process that confers tau toxicity in Drosophila. Cell 116:671-682.

Nishimura T, Kato K, Yamaguchi T, Fukata Y, Ohno S, Kaibuchi K (2004) Role of the PAR-3-KIF3 complex in the establishment of neuronal polarity. Nat Cell Biol 6:328-334.

Nishimura T, Yamaguchi T, Kato K, Yoshizawa M, Nabeshima Y, Ohno S, Hoshino M, Kaibuchi K (2005) PAR-6-PAR-3 mediates Cdc42-induced Rac activation through the Rac GEFs STEF/Tiam1. Nat Cell Biol $7: 270-277$.

Noctor SC, Martinez-Cerdeno V, Ivic L, Kriegstein AR (2004) Cortical neurons arise in symmetric and asymmetric division zones and migrate through specific phases. Nat Neurosci 7:136-144.

Ohshima T, Hirasawa M, Tabata H, Mutoh T, Adachi T, Suzuki H, Saruta K, Iwasato $\mathrm{T}$, Itohara $\mathrm{S}$, Hashimoto $\mathrm{M}$, Nakajima $\mathrm{K}$, Ogawa $\mathrm{M}$, Kulkarni $\mathrm{AB}$, Mikoshiba K (2007) Cdk5 is required for multipolar-to-bipolar transition during radial neuronal migration and proper dendrite development of pyramidal neurons in the cerebral cortex. Development 134:2273-2282.

Panneerselvam S, Marx A, Mandelkow EM, Mandelkow E (2006) Structure of the catalytic and ubiquitin-associated domains of the protein kinase MARK/Par-1. Structure 14:173-183.

Pellettieri J, Seydoux G (2002) Anterior-posterior polarity in C. elegans and Drosophila_PARallels and differences. Science 298:1946-1950.

Reiner O, Coquelle FM, Peter B, Levy T, Kaplan A, Sapir T, Orr I, Barkai N, Eichele G, Bergmann S (2006) The evolving doublecortin (DCX) superfamily. BMC Genomics 7:188. 
Rio C, Rieff HI, Qi P, Khurana TS, Corfas G (1997) Neuregulin and erbB receptors play a critical role in neuronal migration. Neuron 19:39-50.

Schaar BT, Kinoshita K, McConnell SK (2004) Doublecortin microtubule affinity is regulated by a balance of kinase and phosphatase activity at the leading edge of migrating neurons. Neuron 41:203-213.

Schneider A, Laage R, von Ahsen O, Fischer A, Rossner M, Scheek S, Grunewald S, Kuner R, Weber D, Kruger C, Klaussner B, Gotz B, Hiemisch H, Newrzella D, Martin-Villalba A, Bach A, Schwaninger M (2004) Identification of regulated genes during permanent focal cerebral ischaemia: characterization of the protein kinase 9b5/MARKL1/MARK4. J Neurochem 88:1114-1126.

Schwamborn JC, Puschel AW (2004) The sequential activity of the GTPases Rap1B and Cdc42 determines neuronal polarity. Nat Neurosci 7:923-929.

Schwarz A, Futerman AH (1996) The localization of gangliosides in neurons of the central nervous system: the use of anti-ganglioside antibodies. Biochim Biophys Acta 1286:247-267.

Shi SH, Jan LY, Jan YN (2003) Hippocampal neuronal polarity specified by spatially localized mPar3/mPar6 and PI 3-kinase activity. Cell 112:63-75.

Shu T, Ayala R, Nguyen MD, Xie Z, Gleeson JG, Tsai LH (2004) Ndell operates in a common pathway with LIS1 and cytoplasmic dynein to regulate cortical neuronal positioning. Neuron 44:263-277.

Solecki DJ, Model L, Gaetz J, Kapoor TM, Hatten ME (2004) Par6alpha signaling controls glial-guided neuronal migration. Nat Neurosci 7:1195-1203.

Solecki DJ, Govek EE, Tomoda T, Hatten ME (2006) Neuronal polarity in CNS development. Genes Dev 20:2639-2647.

Stepanova T, Slemmer J, Hoogenraad CC, Lansbergen G, Dortland B, De Zeeuw CI, Grosveld F, van Cappellen G, Akhmanova A, Galjart N (2003) Visualization of microtubule growth in cultured neurons via the use of EB3-GFP (end-binding protein 3-green fluorescent protein). J Neurosci 23:2655-2664.

Tabata H, Nakajima K (2003) Multipolar migration: the third mode of ra- dial neuronal migration in the developing cerebral cortex. J Neurosci 23:9996-10001.

Tanaka T, Serneo FF, Higgins C, Gambello MJ, Wynshaw-Boris A, Gleeson JG (2004) Lis1 and doublecortin function with dynein to mediate coupling of the nucleus to the centrosome in neuronal migration. J Cell Biol 165:709-721.

Tassan JP, Le Goff X (2004) An overview of the KIN1/PAR-1/MARK kinase family. Biol Cell 96:193-199.

Timm T, Li XY, Biernat J, Jiao J, Mandelkow E, Vandekerckhove J, Mandelkow EM (2003) MARKK, a Ste20-like kinase, activates the polarityinducing kinase MARK/PAR-1. EMBO J 22:5090-5101.

Timm T, Matenia D, Li XY, Griesshaber B, Mandelkow EM (2006) Signaling from MARK to tau: regulation, cytoskeletal crosstalk, and pathological phosphorylation. Neurodegener Dis 3:207-217.

Tsai JW, Chen Y, Kriegstein AR, Vallee RB (2005) LIS1 RNA interference blocks neural stem cell division, morphogenesis, and motility at multiple stages. J Cell Biol 170:935-945.

Tsai JW, Bremner KH, Vallee RB (2007) Dual subcellular roles for LIS1 and dynein in radial neuronal migration in live brain tissue. Nat Neurosci 10:970-979.

Tsai LH, Gleeson JG (2005) Nucleokinesis in neuronal migration. Neuron 46:383-388.

Watabe-Uchida M, John KA, Janas JA, Newey SE, Van Aelst L (2006) The Rac activator DOCK7 regulates neuronal polarity through local phosphorylation of stathmin/Op18. Neuron 51:727-739.

Xie Z, Sanada K, Samuels BA, Shih H, Tsai LH (2003) Serine 732 phosphorylation of FAK by Cdk5 is important for microtubule organization, nuclear movement, and neuronal migration. Cell 114:469-482.

Zimmer C, Tiveron MC, Bodmer R, Cremer H (2004) Dynamics of Cux2 expression suggests that an early pool of SVZ precursors is fated to become upper cortical layer neurons. Cereb Cortex 14:1408-1420. 